\title{
A ordem patrimonialista e os modais do sistema de transporte coletivo da cidade do Rio de Janeiro
}

\author{
The patrimonial order and the modals of the collective system transportation of the city of Rio \\ de Janeiro
}

\author{
Aline Rozenthal de Souza Cruz \\ Doutoranda em Geografia pela Universidade Federal Fluminense, Brasil \\ alinecruz@live.com
}

\begin{abstract}
Resumo
O presente trabalho estuda a gestão público-privada dos modais do sistema de transportes coletivos da cidade do Rio de Janeiro nos últimos trinta anos. Ou seja, investiga as práticas patrimonialistas e suas contradições que permeiam os processos de concessões e privatizações, os quais são, por vezes, marcados pela efetivação de domínios territoriais urbanos e extração de rendas monopolistas, de modo a dificultar uma mobilidade universal. Assim, se desenvolve um diálogo entre a perspectiva crítica de estudos urbanos e o pensamento social brasileiro, a fim de englobar a totalidade espacial, desvelar os mecanismos invisíveis da ordem distante, e trazer as especificidades das conjunturas políticas e econômicas brasileiras. Neste sentido, nos são caros, por um lado, os conceitos de patrimonialismo e formação social em autores como Weber (2004) e Faoro (1993, 2001); e, de outro, os conceitos de produção do espaço, empresariamento urbano e mobilidade urbana. Além disso, em termos metodológicos, a pesquisa lançou mão de levantamento bibliográfico e documental, exame das licitações, e análise dos relatórios das Comissões Parlamentares de Inquérito (CPI) das Barcas e dos Transportes/Ônibus.
\end{abstract}

Palavras-chave: Mobilidade Urbana, Neoliberalismo, Patrimonialismo.

\begin{abstract}
This paper studies the public-private management of the modalities of the collective transportation system of the city of Rio de Janeiro in the last thirty years. That is, it investigates the patrimonial practices and their contradictions that permeate the processes of concessions and privatisations, which are sometimes marked by the realisation of urban territorial domains and the extraction of monopoly incomes, in order to hinder universal mobility. Thus, a dialogue is developed between the critical perspective of urban studies and Brazilian social thought, in order to encompass the spatial totality, to unveil the invisible mechanisms of the distant order, and to bring the specificities of the Brazilian political and economic conjunctures. In this sense, we are expensive, on the one hand, the concepts of patrimonialism and social formation in authors like Weber (2004) and Faoro (1993, 2001); and, on the other hand, the concepts of space production, urban entrepreneurship and urban mobility. Also, in methodological terms, the research has used bibliographical and documentary surveys, examination of bids, and analysis of the reports of the Parliamentary Commissions of Inquiry (CPI) of Barges and Transport / Buses.
\end{abstract}

Keywords: Urban Mobility, Neoliberalism, Patrimonialism. 


\section{INTRODUÇÃO}

No fim dos anos de 1980, o Brasil enfrentava logo no primeiro governo civil após vinte e um anos de regime ditatorial, uma forte recessão econômica marcada por elevados índices de desemprego e baixos salários. Esse contexto da chamada década perdida, associado ao impacto em âmbito mundial do Consenso de Washington, consequentemente, se refletiu no espaço, de modo a intensificar os processos de urbanização e favelização, em especial, nas metrópoles do sudeste brasileiro, com destaque, para a cidade do Rio de Janeiro. Mesmo com esses entraves ao desenvolvimento e a instabilidade social e política no período, a abertura democrática do país prosseguiu e se consolidou na década de 1990. Ademais, para o entendimento totalizante do referido processo, é necessário vincular as políticas públicas desde então, com as transformações ocorrentes no capitalismo mundial, uma vez que aquelas passaram a se apoiar mais em dinâmicas de financeirização, liberalização econômica e negociações externas.

Sendo assim, é a partir dos governos de Itamar Franco (1992-1994) e, sobremaneira, Fernando Henrique Cardoso (1995-1998 e 1999-2002), que essas novas estratégias de ação do capital, através de um diálogo constante com as ações do poder público, intensificaram as desigualdades urbano-territoriais e a deterioração da vida do trabalhador, ao privilegiar uma maior participação da iniciativa privada através de concessões e privatizações, em especial nas áreas urbanas das grandes metrópoles. Desta maneira, a referida abertura para o mercado, significou uma autonomia relativa do Estado e uma certa fragilidade de suas instituições, ademais porque o modelo político e econômico brasileiro, a partir da Constituição de 1988, é descentralizado (SOUZA, 2001). Isso facilita a ação das políticas públicas no espaço urbano conforme interesses privados. Porém, salienta-se que, esse fato repercute não necessariamente no modo como o espaço urbano é socialmente produzido, pois historicamente esse processo é pleno de disputas, mas em como ele é desigualmente apropriado e gera formas urbanas segregadas (CARLOS, 2013).

Um exemplo marcante dessa rodada neoliberalizante ${ }^{1}$ e de seus subjacentes rearranjos espaciais, vistos pelo viés da formação de novas coalizões de poder, pode ser percebido nas concessões e privatizações dos modais do sistema de transporte coletivo da cidade do Rio de Janeiro. Durante as gestões de Marcello Alencar (1995-1999) no governo do estado e de Luiz Paulo Conde (1997-2001) na Prefeitura do Rio se firmou, em dezembro de 1997, o Consórcio Opportrans. Este viabilizou o direito de exploração dos serviços metroviários durante 20 anos, dando início, a empresa MetrôRio $^{2}$, responsável por operar e administrar as linhas 1 e 2 do metrô e o pré-metrô. Esta realizou

\footnotetext{
${ }^{1}$ Entende-se por neoliberalização o aprofundamento da mercantilização do espaço e, a aplicação das lógicas mercantis aos serviços públicos, como pode ser visto em trabalhos como os de Neil Brenner, Jamie Peck e Nik Theodore (Mar 2012, Jan/Jun 2012) e Carlos Antônio Brandão (2017).

${ }^{2}$ Em dezembro de 2009, a MetrôRio passou a fazer parte do Grupo Invepar (Investimentos e Participações em Infraestrutura S.A), responsável por administrar também as empresas: Concessionária Auto Raposo Tavares (CART) em São Paulo, Linha Amarela S.A no Rio de Janeiro (LAMSA) e a Concessionária Litoral Norte (CLN) na Bahia (METRORIO).
} 
aprimoramentos nos serviços, porém a continuidade de expansão do sistema permaneceu a cargo do governo do estado através da empresa Rio Trilhos (METRORIO). No ano seguinte, 1998, os cerca de $270 \mathrm{~km}$ da Rede Ferroviária Federal S.A. foram privatizados, e a operação dos trens passou a ser responsabilidade da empresa SuperVia ${ }^{34}$. Entretanto, somente em maio de 2001, criou-se a Companhia Estadual de Engenharia de Transportes e Logística (CENTRAL) para melhorar a fiscalização e controle da rede (SUPERVIA). Ainda em 1998, a mesma tendência se efetivou com o tráfego marítimo de passageiros pela Baía de Guanabara. O modal passou das mãos do estado do Rio de Janeiro para retornar a iniciativa privada, que fundou a empresa Barcas S.A.. Mas, foi somente a partir de 2012 que o Grupo $\mathrm{CCR}^{5}$, atual administrador, assinou o contrato de compra e venda para aquisição de $80 \%$ do capital social da concessionária, a qual passou a ser denominada CCR Barcas ${ }^{6}$ (GRUPOCCR).

Então, a partir dos anos FHC uma nova visão, marcada pelo empresariamento, se consolidou sobre a governança metropolitana e a mobilidade urbana. Esta deveria ser calcada numa maior participação da iniciativa privada, ou seja, num desmonte do Estado para abrir caminho para o mercado. Isso acabou por reestruturar as relações sociais de produção do espaço urbano, e a forma como se utiliza o sistema de transporte coletivo do Rio de Janeiro no cotidiano, ao intensificar a acumulação via espoliação (HARVEY, 2014; FONTES, 2010).

Essas tendências de concessões e privatizações, que propiciam a formação de novas coalizões de poder, se enraizaram de tal maneira no capitalismo brasileiro e nas dinâmicas urbanas, que nos governos seguintes, de Luiz Inácio Lula da Silva (2002-2009) e Dilma Rousseff (2010-2015), essas características de ação do poder público, contraditoriamente, talvez tenham até se intensificado (MARICATO, 2011). A efervescência econômica vivida no período, calcada no elevado preço dos royalties do petróleo ${ }^{7}$, no incentivo ao consumo interno de bens duráveis ${ }^{8}$, no apoio político e

\footnotetext{
${ }^{3}$ A SuperVia, atualmente, administra cinco ramais ferroviários e 102 estações, transportando cerca de 600 mil passageiros por dia (SUPERVIA).

4 "Em 2011, a Odebrecht TransPort, empresa com foco em mobilidade urbana, concessões rodoviárias, sistemas integrados de logística e aeroportos, assumiu o controle acionário da SuperVia. Em 2015, a Odebrecht TransPort associou-se à Mitsui e criou a Odebrecht Mobilidade, grupo do qual a SuperVia faz parte" (SUPERVIA).

${ }^{5}$ O Grupo CCR é uma das maiores empresas de concessão de infraestrutura do mundo. No Brasil está presente no setor de transporte de passageiros por meio de concessionárias como ViaQuatro em São Paulo, CCR Metrô Bahia em Salvador e Lauro de Freitas, e ViaRio, responsável pela construção e operação do corredor TransOlímpico. Além disso, detém participação no VLT Carioca, o Veículo Leve sobre Trilhos que circula nas áreas centrais e portuárias do Rio de Janeiro. Mas, o grupo tem negócios correlatos, como administração aeroportuária e transmissão de dados de alta capacidade através de fibra ótica (GRUPO CCR).

${ }^{6}$ Atualmente, a CCR Barcas oferece na Região Metropolitana do Rio de Janeiro (RMRJ), os trajetos: Praça Araribóia (Niterói) x Praça XV (Rio de Janeiro), Charitas (Niterói) x Praça XV (Rio de Janeiro), Praça XV (Rio de Janeiro) x Paquetá (Rio de Janeiro) e Praça XV (Rio de Janeiro) x Cocotá (Rio de Janeiro) (GRUPOCCR).

${ }^{7}$ Elevados preços do barril de petróleo entre 2006 e 2008, e depois entre 2010 e 2014 (MARIANI et al., 2016).

${ }^{8}$ Facilitação de compra do carro próprio através de políticas de redução de impostos e financiamentos.
} 
financeiro a empresas nacionais de variados $\operatorname{ramos}^{9}$, na promoção de megaeventos esportivos ${ }^{10}$, e na aplicação do Plano de Aceleração do Crescimento ${ }^{11}$ (PAC) podem estar entre as razões para tal.

Mas, sem dúvida, reverberaram de modo mais latente no Rio de Janeiro, na época sob gestão do Prefeito Eduardo Paes (2009-2016) e dos Governadores Sérgio Cabral Filho (2007-2014) e Luiz Fernando Pezão (2014-2018). Dentre os motivos para tal, pode-se destacar a importância e influência da metrópole nos referidos setores, bem como o fato desta ter sido a principal sede do Pan Americano (2007), da Copa das Confederações (2013), da Copa do Mundo (2014) e das Olimpíadas (2016). Tais comitês organizadores demandavam melhorias na locomoção e acessibilidade urbana de modo geral, bem como a construção de locais propícios a realização dos eventos. Isso levou o poder público, principalmente na figura do gestor municipal, a realizar um verdadeiro "choque de ordem" ao coibir transportes piratas e recapear importantes vias da cidade (REDAÇÃO O GLOBO, 2009). Além disso, em 2010 abriu-se licitação para conceder ${ }^{12}$ a quatro empresas privadas o controle do transporte por ônibus pelos próximos 20 anos, como uma forma de visar a racionalização das linhas e a diminuição dos congestionamentos (REDAÇÃO DO JORNAL DO BRASIL, 2010). Associado a essa concessão, se lançou o Bilhete Único Carioca, que permitiu economizar no pagamento das tarifas.

Assim, os usuários de transporte coletivo passaram a enfrentar um cotidiano de obras nas vias públicas e no sistema de transportes, que mudavam rotas, tarifas, e se orientavam rumo a Zona Oeste. Na Zona Oeste se destaca a região da Barra da Tijuca, uma área de expansão urbana relativamente recente e idealizada para se tornar uma nova centralidade urbana desde a década de 1970, conforme o plano urbanístico de Lúcio Costa. Entretanto, para essa se consolidar como uma centralidade, ainda faltava a implantação de um sistema de transporte coletivo mais eficiente, já que até o início das obras em mobilidade na gestão Paes, a circulação na Barra da Tijuca era essencialmente baseada no uso do automóvel particular.

Desta maneira, se firmaram parcerias entre as três escalas do poder (federal, estadual e municipal) e grandes empresas imobiliárias e de transportes ${ }^{13}$, de modo a colocar em prática os planos do metrô Linha 4, da racionalização dos ônibus e dos vários corredores BRT (Bus Rapid Transit), como o TransCarioca, o TransOlímpico e o TransOeste. Além disso, na referida área também se

\footnotetext{
${ }_{9}^{9}$ No período merece destaque os incentivos a construção civil, pois o governo federal firmou parcerias com grandes construtoras e incorporadoras brasileiras.

${ }^{10}$ Realização do Pan Americano no Rio de Janeiro em 2007, da Copa das Confederações em 2013, da Copa do Mundo em 2014 e dos Jogos Olímpicos no Rio de Janeiro em 2016.

${ }^{11}$ Criado em 2007, o PAC promoveu a retomada do planejamento e execução de grandes obras de infraestrutura social, urbana, logística e energética no país, contribuindo para desenvolvimento econômico. Assim, o PAC contribuiu para o aumento da oferta de empregos e na geração de renda, elevando investimentos públicos e privados. Dentre as obras do PAC no Rio de Janeiro se destaca a construção do corredor TransCarioca, inaugurado em 2013, e a construção de condomínios do Programa Minha Casa, Minha Vida (PAC).

${ }^{12}$ Pela primeira vez, as empresas de ônibus deixariam de ser permissionárias para se tornarem concessionárias, o que permitiria ao poder público ter maior controle sobre o sistema.

${ }^{13}$ Para a efetivação das obras se fez necessário acordos com as elites locais, principalmente do ramo de transportes, a exemplo das empresas pertences a Jacob Barata Filho, e com proprietários fundiários, como Carlos Carvalho, dono da incorporadora Carvalho Hosken, conforme dados apresentados na pesquisa de Cosentino (2016).
} 
instalou o Parque Olímpico, a Vila dos Atletas e o Campo de Golfe, importantes obras relacionadas as Olimpíadas.

Esses acordos possibilitam a formação de coalizões de poder entre o público e o privado, e entre o local e o nacional, que historicamente já ocorriam, mas que se intensificaram, se complexificaram e, de certa maneira, determinaram a consolidação de monopólios espaciais ${ }^{14}$ (SILVA, 1992; HARVEY, 2006, 2014, 2016). Isso leva a pensar se o modo de acumulação capitalista no Brasil, em especial nas últimas três décadas, favorece a práticas patrimonialistas no âmbito urbano, com destaque para o sistema de transporte coletivo.

Como pressuposto, pode-se dizer que sim, pois muitos trabalhos, com notoriedade o de Raymundo Faoro, intitulado "Os donos do Poder: Formação do Patronato Político Brasileiro” (2001), atestam que a prática do patrimonialismo de Estado, ou seja, a captura das ações do Estado pelos interesses das empresas privadas, é algo histórico e inerente a maneira como se efetivou a política do país. Porém, como entender esse nexo entre o público e o privado no sistema de transportes do Rio de Janeiro? Alguns estudos já colaboraram com essa reflexão como "Os Transportes Coletivos no Rio de Janeiro" de Maria Laís Pereira da Silva (1992), e o recente "Transição Regulatória no transporte por ônibus na cidade do Rio de Janeiro" de Igor Pouchain Matela (2014). Entretanto, algumas lacunas ainda precisam ser preenchidas dada a natureza estruturante do sistema de transportes no processo de produção do espaço urbano e a influência das conjunturas políticas e econômicas sobre o cotidiano de mobilidade da população. Dentre essas lacunas merece destaque a necessidade de investigações acadêmicas sobre a CPI das Barcas de 2009 e a CPI dos Transportes/Ônibus de 2018.

Isso posto, se questiona aqui, em que medida as privatizações e concessões ocorridas nos modais do sistema de transporte coletivo da cidade do Rio de Janeiro, sobretudo a partir dos anos de 1990, apresentam características relacionadas a práticas patrimonialistas capazes de influenciar a reprodução da força de trabalho no espaço urbano?

Nessa linha, o que se objetivou foi desvendar os laços invisíveis que permeiam a ordem distante $^{15}$, ou seja, entender as relações entre o poder público e as empresas privadas de transporte coletivo, e relacioná-las com a ordem próxima ${ }^{16}$, com o cotidiano do usuário. Dito de outra forma, o que se almejou foi investigar como essas coalisões de poder influenciam no ordenamento urbanoterritorial e, consequentemente, na reprodução da força de trabalho, sobremaneira nas últimas três

\footnotetext{
${ }^{14}$ Os monopólios espaciais para Silva (1992) são a fusão dos capitais fundiários, produtivos e espoliativos, de modo a efetuar mecanismos de dominação no entorno dos modais de transporte coletivo. Já David Harvey discute a relação entre monopólios e geografia em três importantes livros: "A produção capitalista do espaço" (2006), "Os limites do capital” (2013) e "17 contradições e o fim do capitalismo" (2016).

${ }^{15}$ Ordem distante é um conceito lefebvreano que se refere aos valores de troca e como estes são, de certa forma, estipulados pelo Estado e pelo mercado. Portanto, a ordem distante apresenta invisibilidades.

${ }^{16}$ Ordem próxima é um conceito lefebvreano que diz respeito aos valores de uso e como estes são vivenciados no cotidiano dos trabalhadores.
} 
décadas, quando as políticas de viés neoliberalizante ao promoverem privatizações e concessões no transporte coletivo, intensificaram as disputas por monopólios espaciais e agravaram as condições de mobilidade urbana (LÉVY, 2002; BARBOSA, 2014).

\section{METODOLOGIA}

O período analisado recai sobre os últimos trinta anos de políticas neoliberalistas no Brasil, mais precisamente entre 1988 e 2018, com destaque para os governos de Itamar Franco (1992-1994), Fernando Henrique Cardoso (1995-2002), Luís Inácio Lula da Silva (2003-2010), Dilma Roussef (2011-2016) e Michel Temer (2016-2018). O recorte espacial abordado é a cidade do Rio de Janeiro e seus principais modais de transporte que sofreram processos de privatização e concessão, como o metrô, os trens urbanos, as barcas e as linhas de ônibus, incluídos os corredores de BRT.

O levantamento bibliográfico, documental e iconográfico dialogou duas linhas teóricometodológicas, de um lado o materialismo histórico dialético, com um forte aporte nas ideias de Henri Lefebvre; e, de outro o pensamento político e social brasileiro, que se inspirou em Max Weber. Sabese que ambos diferem em seus métodos analíticos, bem como sobre definições conceituais como as de Estado e Sociedade Civil, porém acredita-se aqui que elas apresentam complementações fundamentais a interpretação do objeto proposto.

Além disso, se buscou dados empíricos, estatísticos e cartográficos nos sites de órgãos como a Associação Nacional de Transportes Públicos (ANTP), o Instituto de Pesquisas Econômicas (IPEA), o Instituto Brasileiro de Geografia (IBGE), a Prefeitura Municipal do Rio de Janeiro, a Companhia Estadual de Transporte e Logística (CENTRAL), o MetrôRio e a SuperVia. Como complemento a esta etapa, se analisaram informações contidas em jornais, revistas e portais de notícias da internet, bem como os textos das licitações, os relatórios das CPIs das Barcas e dos Transportes/Ônibus, e do dossiê olímpico.

A pesquisa apresentada aqui é parte de uma tese em desenvolvimento no Doutorado em Geografia da Universidade Federal Fluminense, e por isso os dados de campo ainda estão sendo apurados. Mas, já se realizou a aplicação de formulários on-line destinados aos usuários, para aumentar o contato da pesquisadora com o cotidiano no transporte.

\section{DISCUSSÃO TEÓRICA}

O pensamento social brasileiro apresenta uma vasta influência do conceito de patrimonialismo, bem como diferentes interpretações a partir da formulação original do mesmo, que foi elaborado por Max Weber (2004). Dentre os autores que se debruçaram sobre o conceito, podese destacar Sérgio Buarque de Holanda (1995), Simon Schwartzman (1988), e os que são considerados aqui, como principais referências sobre o assunto, Raymundo Faoro (1993, 2001) e 
Florestan Fernandes (2006). Até hoje, a ideia de patrimonialismo continua sendo central para o entendimento das relações que perpassam a formação da sociedade e do Estado ${ }^{17}$ brasileiros, tanto que continua sendo vastamente explorada. Entretanto, isso acabou por levar a distorções e aplicações equivocadas do conceito, inclusive suscitando dúvidas quanto a sua validade, como nos trabalhos de Jessé de Souza (2015) e Werneck Vianna (1999). Assim, se impõe a necessidade de discutir e analisar profundamente o modo como o patrimonialismo assumiu e assume na sociedade, e, no caso, nas alianças que corroboraram para a estruturação do atual sistema de transporte coletivo no Rio de Janeiro.

É importante esclarecer que, o referido conceito está diretamente relacionado à formação social brasileira, a qual não é pautada em um tipo "tropical de feudalismo", mas sim no que Raymundo Faoro (2001) denominou patrimonialismo. Inspirado na sociologia weberiana, Faoro (1993) diz que, na verdade, a dialética não se daria entre a sociedade civil e o Estado no Brasil, mas sim entre governantes e governados, “debilitados estes, como escreveu Max Weber, diante de 'um grupo burocrático, burocraticamente estratificado', cuja tradução seria uma ordem política autocrática" (FAORO, 1993, p.16). Essa tipologia social é o patrimonialismo, um subtipo da ideia de dominação tradicional ${ }^{18}$ em Weber (2004), e que inclui também o patriarcalismo e a gerontocracia. Para Faoro (1993), o patrimonialismo se rege por uma racionalidade material, ou seja, obedece, principalmente, a valores políticos e que não limitam o poder público. Assim, é importante destacar que o modo como se deu e ainda permanece o patrimonialismo no Brasil, é advindo de uma mescla entre as heranças do patrimonialismo português e do impacto do capitalismo liberal inglês ou neoliberal americano, como se pôde notar ao realizar um levantamento histórico sobre as concessões nos transportes cariocas. A exemplo, o monopólio conseguido pela companhia The Leopoldina Railway Ltda, que no início do século XX dava aos ingleses, o controle sobre linhas férreas e as barcas que faziam a travessia na Baía de Guanabara.

Em se tratando dos últimos 30 anos no Brasil, Faoro (1993) faz interessantes reflexões em seu artigo "A aventura liberal numa ordem patrimonialista", ao afirmar que o capitalismo no Brasil é politicamente orientado, pois "controla, fomenta, estimula e faz da economia um apêndice do poder público" (FAORO, 1993, p.17). Além disso aponta que, uma sociedade permeada por essas relações nunca será independente, pois é a política que lhe ditará as condutas. Portanto,

[p]ara que haja o patrimonialismo é necessário que os recursos econômicos e administrativos (em sentido amplo) dependam do poder soberano ou do poder público, que atua por meio de concessões, estímulos, subsídios e autorizações. A empresa é, dessa forma, uma iniciativa

\footnotetext{
${ }^{17}$ O Estado é definido por Weber como "uma relação de dominação do homem sobre o homem, fundada no instrumento da violência legítima" que só pode existir "sob a condição de que os homens dominados se submetam à autoridade continuamente reivindicada pelos dominadores" (WEBER, 2008, p. 57 apud JUNIOR, 2012, p.12).

${ }^{18}$ Para Weber (2004) existem três tipos de dominação: a tradicional, a carismática e a racional-burocrática. No entanto, essa ordem tríplice de dominação sofre imbricações.
} 
particular viável por meio da dádiva pública, obtida por meios legais ou ilícitos. [...] O capitalismo, em circunstâncias tais, ou é uma máscara ou é uma aspiração, aspiração que se pretende realizar com a perseguição de uma sombra. Igualmente, o liberalismo, tanto o político quanto o econômico, sofre de ambiguidades crônicas e anemia congênita, como não podia deixar de ser" (FAORO, 1993, p.17).

Em suma, para Faoro (1993) o patrimonialismo atravessou toda a história brasileira, inclusive se fazendo presente nos planos financeiros das décadas de 1980 e 1990, período no qual se pretende realizar parte da análise. De acordo com o autor isso se faz perceptível através do modo pelo qual as riquezas, bens e propriedades "não pertencem aos particulares, mas a eles estivessem revogavelmente confiados" (FAORO, 1993, p.17).

Outro pensador que se faz importante para o diálogo aqui é Florestan Fernandes (2006), que assim como Faoro (2001) defende que Portugal transplantou os moldes de suas instituições para o Brasil durante o período de colonização, fazendo com que essa seja uma marca não superada ao longo de nossa formação, porém com momentos de intensificação como durante os anos do Império. Além disso, aponta que o modelo de desenvolvimento brasileiro, baseado em grandes latifúndios, favoreceu a concentração estamental do poder e da riqueza, possibilitando apenas a um grupo restrito exercer influência sobre os rumos do país (FERNANDES, 2006). Assim, o Estado passa a ditar os rumos da sociedade nacional, apoiado, em grande medida, pela atuação dos senhores rurais, e configurando o que Fernandes (2006) chama de burocratização da dominação patrimonialista, e que permanece até os dias de hoje, mas sempre se readaptando, e se intensificando na área urbana.

Portanto, apesar de ter havido uma série de movimentos contra o regime, greves e revoltas populares, bem como uma maior penetração do sistema capitalista através de práticas políticoeconômicas mais (neo)liberais, para Faoro (2001) o Estado brasileiro continuou a ser guiado essencialmente por interesses particularistas, pois “"[a] progressiva conformação de uma sociedade nacional, moderna, teria surtido pouco efeito no sentido de alterar essa realidade fundamental" (JUNIOR, 2012, p.22). Já para Fernandes (2006) a burocratização da dominação patrimonialista não se estenderia a todos os âmbitos do Estado, e provocaria, na verdade, uma espécie de dualidade estrutural entre as formas de dominação tradicional e a maneira como o poder se efetiva pela ordem legal. Assim, o poder central do Estado seria atingido indiretamente pela dominação patrimonialista (JUNIOR, 2012).

Ambos os autores trazem relevantes contribuições para o debate, e, serviram de embasamento teórico para outros dois estudos fundamentais para o presente artigo: "O Capitalismo de Laços: os donos do Brasil e suas conexões" de Sérgio G. Lazzarini (2011) e "Transição regulatória no transporte por ônibus na cidade do Rio de Janeiro" de Igor Pouchain Matela (2014). O primeiro fez um mergulho sobre as atuais nuances institucionais do capitalismo brasileiro, e demonstra como nos últimos trinta anos houve uma tendência crescente dos governos em consolidar "grandes grupos 
privados nacionais, culminando com a crise financeira mundial de 2008, que, segundo muitos, selou a 'volta do Estado' como elemento ativo para a capitalização das empresas” (LAZZARINI, 2011, p.10). Desta forma, ao argumentar que o controle efetivo do Estado no processo produtivo teria se ampliado, assim como a influência de alguns agentes privados nacionais, Lazzarini (2011) demonstra que teria se forjado uma rede de laços corporativos bem conectada.

Dentre as razões apresentadas pelo autor para tal, a principal está ligada a forma como se executaram os processos de privatização no país, pois ao invés de se criarem empresas de capital aberto com ações especiais por parte do Estado, “optou-se por vender o controle a determinados grupos nacionais, maximizando-se o prêmio dele derivado e, consequentemente, a receita oriunda da venda" (HADDAD, 2010 in LAZZARINI, 2011, p.14). Porém,

[d]ado o elevado montante envolvido nas transações e os preços mínimos muitas vezes fixados, por razões políticas, acima do mercado na época, a fórmula encontrada para viabilizar a venda foi o estímulo à formação de consórcios, envolvendo fundos de pensão de estatais, em conjunto com empréstimos subsidiados e a participação direta do BNDES. Ou seja, uma parcela significativa da privatização ocorreu com o uso direto e indireto de recursos públicos (HADDAD, 2010 in LAZZARINI, 2011, p.14).

Assim, o referido livro se mostra fundamental para compreender as relações políticas e econômicas que se deram nos últimos dez anos, pois demonstra através de levantamentos empíricos, como age o Estado patrimonialista brasileiro. Neste são evidenciadas restritas redes de agentes, angariadas por recursos públicos, que ditam a produtividade e, consequentemente, o crescimento econômico do país. Portanto, por influírem espacialmente de maneira seletiva, aumentam as suas disparidades, e geram maior concentração de poder monopolista.

Já Matela (2014), se baseando em Lessa e Dain (1982), afirma que o espaço urbano no Brasil sempre foi tido como um “locus privilegiado da acumulação do capital nacional”, e que isso gerou um padrão de regulação estatal fortemente calcado em relações patrimonialistas de lógica liberal. Essa dinâmica garantiu privilégios a "frações do capital nacional predominantes nos circuitos de acumulação que envolviam obras públicas, mercado imobiliário e serviços urbanos (especialmente os de transporte)" (MATELA, 2014, p.17-18). Assim, a análise do autor aponta que o setor de transportes no Rio de Janeiro estaria, na verdade, atravessando um processo de transição regulatória para um novo ciclo de acumulação. Certamente, esse processo ainda está se operando, com menor ou maior intensidade, dado o delicado contexto político-econômico que o Brasil tem atravessado nos últimos cinco anos, mas claramente, ele apresenta tendências a acumulações urbanas centradas em rendas monopolistas (HARVEY, 2013), que acabam por intensificar a diferenciação espacial e a segregação (CARLOS, 2006, 2013). Por fim, cabe destacar que os referidos processos, em termos de uma discussão quanto a estrutura urbana e de uma crítica a economia política do espaço, levam a 
dificuldades de acesso a centralidades urbanas, e consequentemente, a perda da urbanidade, conforme aponta Lefebvre $(2005,2006)$.

\section{CONSIDERAÇÕES FINAIS}

Os resultados parciais conseguidos a partir do entrelaçamento entre os levantamentos bibliográfico e documental, e a aplicação dos formulários, apontaram que a formação de cartéis no sistema de transporte da cidade do Rio de Janeiro é algo historicamente e socialmente reconhecido, conforme demonstrado em pesquisas anteriores. Mas, o que se notou nos últimos anos foi a presença mais forte de certos agentes, escolhidos pelo aval do poder público, serem capazes de ditar as tendências de urbanização, valorização imobiliária e controlar a circulação da força de trabalho. Destaca-se a relação do grupo Odebrecht, alvo de muitas investigações com o Estado, tanto na construção e administração de infraestruturas urbanas (como o Estádio Maracanã e a Vila Olímpica), como na gestão de modais a exemplo dos trens suburbanos que compõem a SuperVia. Outro interessante é o grupo Invepar (Investimentos e Participações em Infraestruturas S.A.), um fundo de pensão que ao administrar o MetrôRio (liga a estação Pavuna ao Jardim Oceânico), o Veículo Leve sobre Trilhos (percorre a região portuária e o centro da cidade), e a Linha Amarela (a LAMSA une a Ilha do Fundão a Baixada de Jacarepaguá), tem uma forte influência sobre os preços da tarifas, controle dos fluxos de pessoas e áreas do entorno. Essas e outras poucas empresas de ônibus, dominam todo o sistema de transporte da cidade, e influenciam sobre o valor da terra, detendo o monopólio espacial.

\section{REFERÊNCIAS}

BRANDÃO, C. A. Crise e rodadas de neoliberalização: impactos nos espaços metropolitanos e no mundo do trabalho no Brasil. Caderno Metrópolis, São Paulo, v. 19, n. 38, p. 45-69, 2017.

BRENNER, N. ; PECK, J. ; THEODORE, N. Mal-estar no Pós-neoliberalismo. Novos estudos, n. 92, p. 59-78, 2012.

Após a neoliberalização? Caderno Metrópolis, São Paulo, v. 14, n. 27, p. 15-39, 2012.

CARLOS, A. F. A. Diferenciação socioespacial. Revista Cidades, Presidente Prudente, v. 2, n. 4, p. 221247, 2006.

A. F. A. A prática espacial urbana como segregação e o 'direito à cidade' como horizonte utópico. In: VASCONCELOS, P. A.; CORRÊA, R. L.; PITAUDI, S. M. (Orgs.). A cidade contemporânea: segregação espacial. São Paulo: Editora Contexto, 2013. p. 95-110.

BARBOSA, J. L. A mobilidade urbana como expressão do Direito à Metrópole. In: LIMONAD, E.; CASTRO, E. (Orgs.). Um novo planejamento para um novo Brasil? Rio de Janeiro: Editora Letra Capital, 2014. p. 187-201. 
CONSENTINO, R. Olimpíadas da Barra da Tijuca 2016: a construção de uma nova centralidade no Rio de Janeiro. In: VAINER, C.; BROUDEHOUX, A. N.; SÁNCHEZ, F.; OLIVEIRA, F. L. (Orgs.). Os Megaeventos e a cidade: perspectivas críticas. Rio de Janeiro: Editora Letra Capital, 2016. p. 11-51.

FAORO, R. Os donos do poder: a formação do patronato político brasileiro. 3. ed. Rio de Janeiro: Editora Globo, 2001. 944p

1993.

R. A aventura liberal numa ordem patrimonialista. Revista USP, São Paulo, n. 17, p. 14-29,

FERNANDES, F. A revolução burguesa no Brasil: ensaio de interpretação sociológica. São Paulo: Editora Globo, 2006. 512p.

FONTES, V. O Brasil e o Capital-Imperialismo: Teoria e História. 1. ed. Rio de Janeiro: Editora UFRJ, 2010. 388p.

GRUPO CCR. Sobre o grupo. Disponível em: http://www.grupoccr.com.br/grupo-ccr/sobre-o-grupoccr. Acesso em: 15 abr. 2018.

HADDAD, C. Prefácio. In: LAZZARINI, S. G. Capitalismo de laços: os donos do Brasil e suas conexões. Rio de Janeiro: Editora Elsevier, 2011.p. 1.

HARVEY, D. A produção capitalista do espaço. 1. ed. São Paulo: Annablume, 2006. 252p.

, D. Os limites do capital. 1. ed. São Paulo: Boitempo Editorial, 2013. 842p.

, D. O novo Imperialismo. 8. ed. São Paulo: Edições Loyola, 2014. 208p.

D. 17 contradições e o fim do capitalismo. 1. ed. São Paulo: Boitempo Editorial, 2016. 304p.

HOLANDA, S. B. Raízes do Brasil. 26. ed. São Paulo: Companhia das Letras, 1995. 256p.

LEFEBVRE, H. A produção do espaço. Tradução não-oficial da UFMG. 1. ed. Belo Horizonte: UFMG, 2005. 476p.

, H. O direito à cidade. 6. ed. São Paulo: Editora Centauro, 2006. 146p.

LESSA, C.; DAIN, S. Equívocos e Manipulações da Política Fiscal. In: DAVID, M. D.; TAVARES, M. C.; ASSIS, J. C. (Orgs.). A economia política da crise. Rio de Janeiro: Editora Vozes, 1982.

LÉVY, J. Os novos espaços da mobilidade. GEOgraphia, Niterói, v. 3, n. 6, p. 7-17, 2002.

JÚNIOR, A. P. Florestan Fernandes e o conceito de patrimonialismo na compreensão do Brasil. Revista PLURAL, São Paulo, v. 19, p. 9-27, 2012.

LAZZARINI, S. G. Capitalismo de laços: os donos do Brasil e suas conexões. 1. ed. Rio de Janeiro: Editora Elsevier, 2011. 296p.

MARIANI, D.; ROCHA, J.; DUCROQUET, S.; MAYER, R. Um histórico visual da queda do preço do petróleo. Nexo Jornal. 2016. Disponível em: https://www.nexojornal.com.br/grafico/Um-históricovisual-da-queda-do-preço-do-petróleo. Acesso em: 15 abr. 2018.

MARICATO, E. O impasse da política urbana no Brasil. 1. ed. Petrópolis: Editora Vozes, 2011. 224p. 
MATELA, I. P. Transição regulatória no transporte por ônibus na cidade do Rio de Janeiro. 1. ed. Rio de Janeiro: Editora Letra Capital, 2014. 153p.

I. P. Reestruturação Urbana Neoliberal e as empresas de ônibus na cidade do Rio de Janeiro. Caderno Metrópole, São Paulo, v. 16, n. 31, p. 151-169, 2014.

METRORIO. Disponível em: https://www.metrorio.com.br/Empresa/Sobre. Acesso em: 15 abr. 2019.

PAC. Ministério do Planejamento. Sobre o PAC. Disponível em: http://www.pac.gov.br/sobre-o-pac. Acesso em: 15 abr. 2019.

REDAÇÃO O GLOBO. Reforma da Linha Vermelha tem início nesta Quinta-Feira. Disponível em: http://extra.globo.com/noticias/rio/reforma-da-linha-vermelha-tem-inicio-nesta-quinta-feira203413.html. Acesso em:15 fev. 2017.

REDAÇÃO JORNAL DO BRASIL. Bilhete único entra em vigor em outubro. 2010. Disponível em: http://jbonline.terra.com.br/rio/noticias/2010/04/29/bilhete-unico-entra-em-vigor-em-outubro/. Acesso em: 15 fev. 2017.

REDAÇÃO REVISTA NTUurbano. Transporte passa a ser direito social na Constituição. Revista NTUurbano, v. 3, n. 17, 2015.

SILVA, M. L. P. Os transportes coletivos no Rio de Janeiro. 1. ed. Rio de Janeiro: Coleção Biblioteca Carioca, 1992. 180p.

SOUZA, C. Federalismo e Descentralização na Constituição de 1988: Processo Decisório, Conflitos e Alianças. Revista Dados, Rio de Janeiro, v. 44, n. 3, p. 513-560, 2001.

SOUZA, J. A tolice da inteligência brasileira: ou como o país se deixa manipular pela elite. 1. ed. São Paulo: Editora Leya, 2015. 272p.

SUPERVIA. Quem somos. Disponível em: http://www.supervia.com.br/pt-br/quem-somos. Acesso em: 15 abr. 2019.

SCHWARTZMAN, S. Bases do autoritarismo brasileiro. 2. ed. Rio de Janeiro: Editora Campus, 1988. 296p.

WEBER, M. Economia e Sociedade: fundamentos da sociologia compreensiva. 2. ed. São Paulo: Imprensa Oficial do Estado de São Paulo, 2004. 586p.

VIANNA, L. J. W. Weber e a Interpretação do Brasil. Novos Estudos, São Paulo, v. 53, p. 33-48, 1999.

Trabalho recebido em 08/07/2019

Trabalho aceito em 11/07/19 